CLINICAL STUDY

\title{
The clinical, metabolic and endocrine features and the quality of life in adults with childhood-onset craniopharyngioma compared with adult-onset craniopharyngioma
}

Pat Kendall-Taylor, Peter J Jönsson ${ }^{1}$, Roger Abs $^{2}$, Eva Marie Erfurth ${ }^{3}$, Maria Koltowska-Häggström ${ }^{1}$, David Anthony Price ${ }^{4}$ and Johan Verhelst ${ }^{5}$

University of Newcastle, Newcastle upon Tyne, UK, ${ }^{1}$ KIGS/KIMS Outcomes Research, Pharmacia, Stockholm, Sweden, ${ }^{2}$ Antwerp Metabolic Research Unit, University of Antwerp, Belgium, ${ }^{3}$ University Hospital, Lund, Sweden, ${ }^{4}$ Royal Manchester Children's Hospital, Manchester, UK and ${ }^{5}$ Middelheim Hospital, Antwerp, Belgium

(Correspondence should be addressed to P Kendall-Taylor, SCMS, Floor 4, Leech Building, Medical School, Newcastle upon Tyne NE2 4HH, UK; Email: pat.kendall-taylor@newcastle.ac.uk)

\begin{abstract}
Background: Craniopharyngioma is a parasellar tumour that, although benign, tends to behave aggressively. It can occur at any age but most commonly presents in childhood or adolescence.

Objectives: To investigate the frequency and severity of problems associated with craniopharyngioma, using the large international database (KIMS) for adult patients with GH deficiency (GHD), and to assess the differences between the adult onset (AO, aged 18 or above) disease and adults with childhood onset (CO) craniopharyngioma.

Design: Inclusion criteria were: an established diagnosis of craniopharyngioma, severe GHD and no recent GH treatment. These criteria were fulfilled by 393 (184 female, 209 male) patients; 241

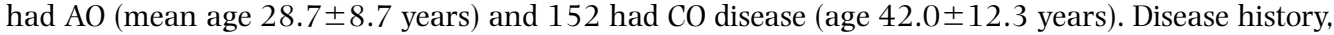
clinical features and anthropometric data were recorded at the time of enrolment in the database, and body composition, serum IGF-I, serum lipids and quality of life (QoL) were assessed.

Results: Peak age at onset of craniopharyngioma was 15-20 years. Ninety percent of patients had been treated surgically. CO patients were shorter than AO patients and had much lower IGF-I standard deviation scores (SDS). The majority had hypopituitarism and over $60 \%$ had diabetes insipidus. Body mass index (BMI) was higher in AO males (30.2 \pm 5.5$)$ than in CO males (28.5 \pm 7.5$)$; waist circumference was also greater. Obesity was more common in AO patients (51.8\% vs $39.1 \%)$. Body composition did not differ between groups. Cholesterol and triglycerides were higher in AO than in CO patients, but high density lipoprotein (HDL)- and low density lipoprotein (LDL)-cholesterol did not differ. Quality of life, assessed by Quality of Life-Assessment of Growth Hormone Deficiency in Adults (QoL-AGHDA) and the Nottingham Health Profile, was markedly reduced in all groups with no significant differences between them; the QoL-AGHDA score correlated with age at onset of both craniopharyngioma and GHD, and also with BMI in AO patients.

Conclusions: These data emphasise the generally poor state of health of patients treated for craniopharyngioma, with respect to endocrine and metabolic function, and also the markedly reduced quality of life. In addition to GHD, most patients have evidence of hypothalamic damage with associated obesity, diabetes insipidus and hypopituitarism. Adults with CO craniopharyngioma were shorter, had lower IGF-I, lower BMI, less obesity and slightly lower blood lipid levels than patients with AO craniopharyngioma.
\end{abstract}

European Journal of Endocrinology $152557-567$

\section{Introduction}

Craniopharyngioma is a parasellar tumour that constitutes about $3 \%$ of all intracranial tumours and up to $10 \%$ of childhood brain tumours. The overall incidence in the USA, determined from two population-based cancer registries, was 1.3 per million person years and did not vary by gender or race (1). In Europe the annual incidence in children was estimated as 1.2 per million (2). It may occur at any age, but most commonly presents in childhood or adolescence. A bimodal distribution by age with peak incidence rates in children (aged 5-14 years) and among older adults was noted (1). Fahlbusch et al. (3) in Europe also noted a bimodal distribution with peak incidences at 15-20 years and another peak at 50-55 years.

These tumours may arise from embryonic squamous remnants of Rathke's pouch; although they are 
histologically benign and rarely undergo malignant change, they are often large and tend to behave aggressively, infiltrating surrounding brain structures and sometimes obstructing the third ventricle. There is significant mortality and morbidity, with reported standardised mortality ratio (SMR) of 5.55 (4) and 9.3 (5). Common problems include short stature, obesity, delayed puberty, visual deficit, hypopituitarism and diabetes insipidus (DI). Craniopharyngiomas are usually treated with surgery, often radical, with or without radiotherapy. Ablation of the tumour commonly results in further loss of anterior pituitary hormones and sometimes of vasopressin also. It has been suggested that the condition may be more severe when it presents in adulthood, but evidence for this seems to be lacking.

The KIMS international database was established to monitor the long-term safety and outcomes of growth hormone $(\mathrm{GH})$ replacement therapy in adults with confirmed GH deficiency (GHD) and as such it provides a useful and valuable resource for analysing the various features of craniopharyngioma.

Data from children with GHD resulting from craniopharyngioma, held in a separate large international database (KIGS) were analysed previously (6), as well as other series from individual centres (7), but to date few studies have examined the late features of craniopharyngioma in adults who have developed their disease in childhood.

The objectives of this study were to use this very large database to provide information concerning the frequency and severity of the problems associated with craniopharyngioma, and to assess if there are significant differences between the childhood onset (CO) and the adult onset (AO) forms of the disease.

\section{Materials and methods}

\section{KIMS database}

The KIMS (Pfizer International Metabolic Database) database was established in 1994 as an ongoing record of adult patients with GHD. The primary objective was to monitor the safety of long-term GH replacement treatment in adult patients with GHD treated in a conventional clinical setting. Data are collected at clinic visits on specially designed case record forms (CRFs). The data collection process is monitored by study monitors who verify the data with the original source documents, and the quality of the data entered has been audited and confirmed. It is a condition of entry to KIMS that each centre obtains approval from their local ethics committee and that patients give informed consent, either verbally or in writing, depending on the local legal requirements. In these 8 years a total of almost 8500 adult patients with GHD have been entered into the database from 28 countries. The analyses for the present study were performed based on the Analysis Dataset of July 2002 that contained 6123 patients of whom 733 were diagnosed with craniopharyngioma.

\section{Patients}

Inclusion criteria for this study were: (a) a diagnosis of craniopharyngioma had been established, (b) all patients had GHD, defined as a peak response to $\mathrm{GH}$ stimulation test of $<3.0 \mu \mathrm{g} / \mathrm{l}$, and (c) no patients had received $\mathrm{GH}$ treatment in the recent past (for at least 6 months) prior to entry into the KIMS database. For diagnosis of GHD, the insulin stress test (IST) was regarded as the primary test when a patient had several tests performed. Where IST was not done data were taken from arginine, arginine/insulin, glucagon and growth hormone releasing hormone (GHRH) tests in that order. If information was not available from any of these tests, the patient was omitted from the study. Individual entry of patients with GHD, considered potentially suitable for $\mathrm{GH}$ replacement treatment was at the discretion of the investigating physician, and thus excluded those with very large tumour mass despite therapy and those in whom it was still too early to judge if treatment had successfully arrested tumour growth.

Of the 733 patients identified, 245 had received $\mathrm{GH}$ within the last 6 months and 95 failed to meet the criteria as defined above; thus the total number of patients with craniopharyngioma fulfilling the criteria was 393 , of whom 184 were female and 209 were male. Patients were designated as either adult-onset (AO), aged 18 years or more, or childhood onset $(\mathrm{CO})$, aged $<18$ years, according to the age of onset of the craniopharyngioma or, when this was not known, the age of diagnosis of GHD. By these criteria 241 had AO and 152 had $\mathrm{CO}$ disease. GHD was diagnosed on the basis of IST in $69.2 \%$ of patients.

The previous treatment for the craniopharyngioma is shown in Table 1 . The majority had had surgical treatment; of those, $70.7 \% \mathrm{CO}$ and $63.7 \%$ AO patients had transcranial surgery and the remainder had surgery by the transsphenoidal approach. Less than half had received radiotherapy, and a small number had no definitive treatment (14 CO and 12 AO patients). Although no patients had received GH in the 6 months or more before entry into the KIMS database, $63.8 \%$ of $\mathrm{CO}$ patients had been treated with $\mathrm{GH}$ at some point in the past, in contrast to only $10.0 \%$ of AO patients.

Table 1 Previous treatment for craniopharyngioma.

\begin{tabular}{lcr}
\hline & CO (\%) & AO (\%) \\
\hline None (no surgery or radiotherapy) & 5.3 & 5.4 \\
Surgery & 90.8 & 90.5 \\
Repeat surgery & 23.2 & 23.7 \\
Radiotherapy (either alone of after surgery) & 44.1 & 35.7 \\
\hline
\end{tabular}




\section{Measurements}

At baseline, disease history and clinical features were recorded together with measurements of height, weight, and waist and hip circumferences.

Body composition, in terms of percentage body fat and lean body mass, was determined by bioelectrical impedance analysis (BIA), or by dual-energy x-ray absorptiometry (DEXA), dependent on the methodology available in each centre.

Serum insulin-like growth factor I (IGF-I) was determined by radioimmunoassay after acid-ethanol precipitation of the binding proteins (Nichols Institute Diagnostics, San Juan Capistrano, CA, USA). Longterm reproducibility (coefficient of variation), measured during a time period of more than one year, was $<9 \%$ in the concentration range $130-850 \mu \mathrm{g} / \mathrm{l}$. The assay detection limit was about $30 \mu \mathrm{g} / \mathrm{l}$. The reference range for the IGF-I assay was adjusted for age. All measurements were conducted in a single central laboratory. Results of IGF-I assay, as well as height and BMI are expressed as standard deviation scores (SDS) to allow for differences of age and gender.

Lipid measurements were all performed in the same central laboratory. Serum concentrations of total cholesterol (8), high density lipoprotein (HDL)cholesterol (9) and triglycerides (10) were measured directly and expressed as $\mathrm{mmol} / \mathrm{l}$. Serum concentrations of low density lipoprotein (LDL)-cholesterol were estimated using Friedewald's formula: LDLcholesterol $=$ total cholesterol minus HDL-cholesterol minus $0.45 \times$ triglycerides (11). The accuracy of this formula decreases when the triglycerides level is above $4.5 \mathrm{mmol} / \mathrm{l}$. The conversion factors are: $1 \mathrm{mmol} / \mathrm{l}=38.46 \mathrm{mg} / \mathrm{dl}$ for cholesterol and $1 \mathrm{mmol} / \mathrm{l}=90.90 \mathrm{mg} / \mathrm{dl}$ for triglycerides. Other measurements, which included hormones and blood chemistry were carried out in the laboratory local to the patient.

Quality of life was assessed using the Quality of Life Assessment of GHD in Adults (QoL-AGHDA) questionnaire and the Nottingham Health Profile (NHP). The QoL-AGHDA is a cross-cultural disease-specific questionnaire (12-14), designed to assess physical and psychological discomfort in adult hypopituitary patients; it has been validated in such patients and for a number of different languages (12). Information regarding personal situation and social functioning was obtained from the Patient Life Situation Form, a questionnaire designed to collect patient-reported outcomes.

\section{Data analysis}

The data analysed here are those obtained at baseline, defined as the point of enrolment in the database. Data analyses were performed using SAS (Statistical Analysis System, SAS Institute, Cary, NC, USA). The significance of effects was determined between groups by unpaired $t$-tests for normally distributed data and by Wilcoxon rank sum tests for other data. Comparisons of proportions were performed using the Fisher exact and Chi-square tests. Significance was accepted with $P$ values of $<0.05$. To adjust for the age difference and possible gender differences a multiple linear regression was performed (MLR); differences are only shown as significant where MLR analysis had demonstrated an effect independent of age and gender. Data are expressed as either means \pm S.D. or median $(90 \%$ confidence limits) as appropriate.

\section{Results}

The cohort of 393 patients comprised 152 CO patients (82 males (M) and 70 females (F)) and 241 AO patients (127 M, 114 F). The ratio of M:F did not differ between the CO (1.17:1) and AO (1.11:1) groups.

\section{Ages at onset of craniopharyngioma and at diagnosis of GHD}

The distribution for age at onset of the craniopharyngioma is shown in Fig. 1A, and the distribution for age at the time of diagnosis of GHD is shown in Fig. 1B. The mean ages at onset of craniopharyngioma, the mean age at the time of GHD diagnosis and the mean age at entry into the KIMS database are shown in Table 2. The duration of GHD is an approximation based on the date of disease onset or of first treatment of the tumour, or if those were not available then the date of GHD diagnosis was used. The long gap between the diagnosis of craniopharyngioma and GHD is notable and greater in the CO group. Not surprisingly, the $\mathrm{CO}$ patients were younger than the $\mathrm{AO}$ patients and the duration of GHD in $\mathrm{CO}$ patients was longer.

\section{Features related to GHD}

AO patients were significantly taller than $\mathrm{CO}$ patients (Fig. 2) and IGF-I SDS was markedly reduced in the CO compared with the AO patients. The difference in height for males between $\mathrm{CO}$ and $\mathrm{AO}$ was significant $(P=0.0110)$ as was that for females $(P=0.0007)$. The differences in IGF-I SDS between $\mathrm{CO}$ and AO for males and females were also highly significant $(P=0.0001)$. IGF-I SDS was higher in males than in females.

There was no significant difference in either height or IGF-I between the $\mathrm{CO}$ patients who had received $\mathrm{GH}$ treatment at some time in the past and those who were truly naïve (never treated with $\mathrm{GH}$ prior to entry into KIMS); height 164.6 vs $166.0 \mathrm{~cm}$ in true naïve vs semi-naïve (previously treated with $\mathrm{GH}$ at least 6 months prior to entering KIMS $)(P=$ not significant (NS)) and IGF-I SDS -4.29 vs -4.51 $(P=\mathrm{NS})$. 
(A)

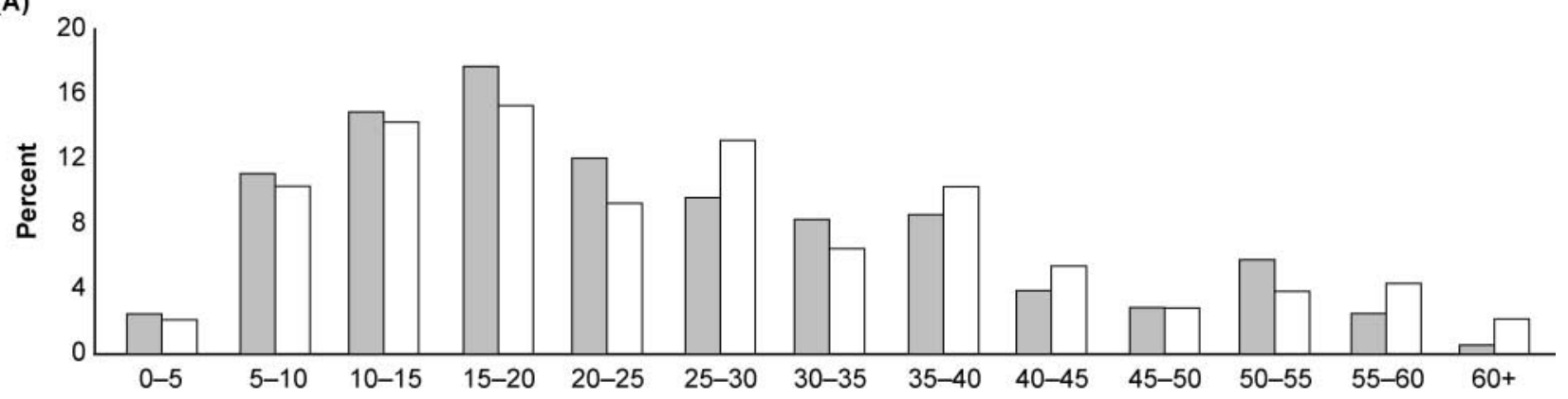

(B)

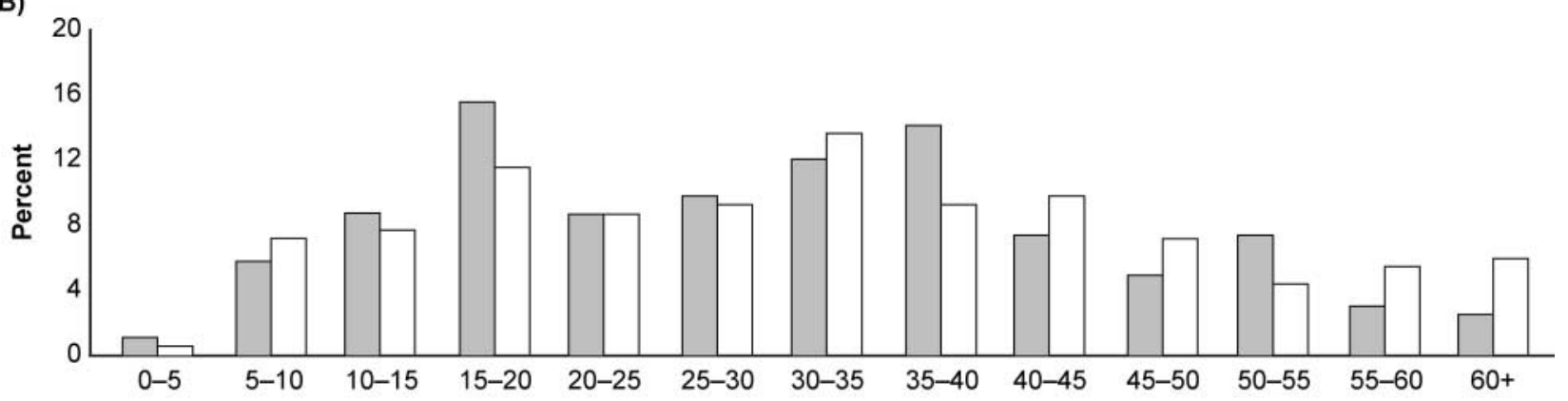

Figure 1 (A) Distribution of ages at onset of the craniopharyngioma. (B) Age at the time of diagnosis of GHD. $\square$, Male; $\square$, female.

A negative correlation of IGF-I SDS was found with estimated duration of GHD for the whole cohort $(\mathrm{R}=-0.41, P=<0.001)$ (Fig. 3). Numbers were too small to investigate the relationship between time since the last treatment with GH and IGF-I SDS.

A positive correlation of IGF-I SDS was found with BMI and BMI SDS (Fig. 4) in the whole cohort (males: $n=116, \quad r=0.27, \quad P=0.003 ;$ females: $n=126$, $\mathrm{r}=0.23, P=0.011)$. This correlation of IGF-I SDS with BMI was significant only in AO $(n=158$, $P=0.008$ ) but not in CO patients, and it applied particularly to female AO patients $(n=85, P=0.011)$.

\section{Other endocrine features}

Almost all patients had additional anterior pituitary hormone deficiencies and $60 \%$ also had DI (Table 3 ). There were no differences between the $\mathrm{CO}$ and $\mathrm{AO}$ patients with respect to the number of additional hormone deficiencies: $57.9 \%$ of $\mathrm{CO}$ and $59.8 \%$ of $\mathrm{AO}$ patients were panhypopituitary and only $1 \%$ in each group were eupituitary. Frequency of individual

Table 2 Mean ages and duration of GHD in years ( \pm S.D.).

\begin{tabular}{llr}
\hline & \multicolumn{1}{c}{ CO } & \multicolumn{1}{c}{ AO } \\
\hline Age at onset of craniopharyngioma & $11.8 \pm 4.2$ & $34.3 \pm 12.0$ \\
Age at diagnosis of GHD & $19.7 \pm 11.1$ & $39.08 \pm 12.8$ \\
Age at entry to KIMS database & $28.7 \pm 8.7$ & $42.0 \pm 12.3$ \\
Estimated duration of GHD & $16.9 \pm 9.7$ & $7.8 \pm 7.4$ \\
\hline
\end{tabular}

hormone deficiencies was as follows: adrenocorticotrophin (ACTH) 86.8 vs $89.6 \%$, luteinizing hormone/ follicle-stimulating hormone (LH/FSH) 95.4 vs $94.2 \%$, thyrotrophin (TSH) 94.1 vs $92.1 \%$ for $\mathrm{CO}$ and $\mathrm{AO}$ patients respectively. Patients who had no surgical treatment had slightly less severe hypopituitarism (mean deficit of 2.89 \pm 1.09 hormones) than those who had had surgery (mean deficit 3.43 \pm 0.87 hormones, $P<0.01$ ) but the number of hormone deficiencies did not correlate with the number of operations performed. Patients who had transsphenoidal surgery had a mean deficit of $3.22 \pm 0.99$ hormones compared with the transcranial approach (3.48 $\pm 0.80, P<0.05)$. The number of pituitary hormone deficiencies did not correlate significantly with the presence of visual field defects. DI occurred more frequently in patients who had had surgery and was present in 236 of $364(64.8 \%)$ patients compared with 9 of $27(33.3 \%)$ who had had no surgery $\left(\chi^{2}=10.66, P=0.0011\right)$. The number of operations did not affect the frequency of DI, neither was DI more frequent in patients who had radiotherapy in addition to surgical treatment. DI correlated with BMI SDS $(\mathrm{R}=0.168, P=0.001)$ in the whole cohort and in $\mathrm{CO}$ patients, although not in AO patients.

Data for puberty were incomplete. However, delayed puberty was common in the male CO patients $(70.5 \%$ of 78) compared with $11.5 \%$ (of 200) in AO patients; $78.0 \%$ of $\mathrm{CO}$ and $8.2 \%$ of $\mathrm{AO}$ males required induction of puberty. The findings in females were parallel, although again the data are incomplete: the mean age at menarche was 16.4 years in $\mathrm{CO}$ and 13.7 

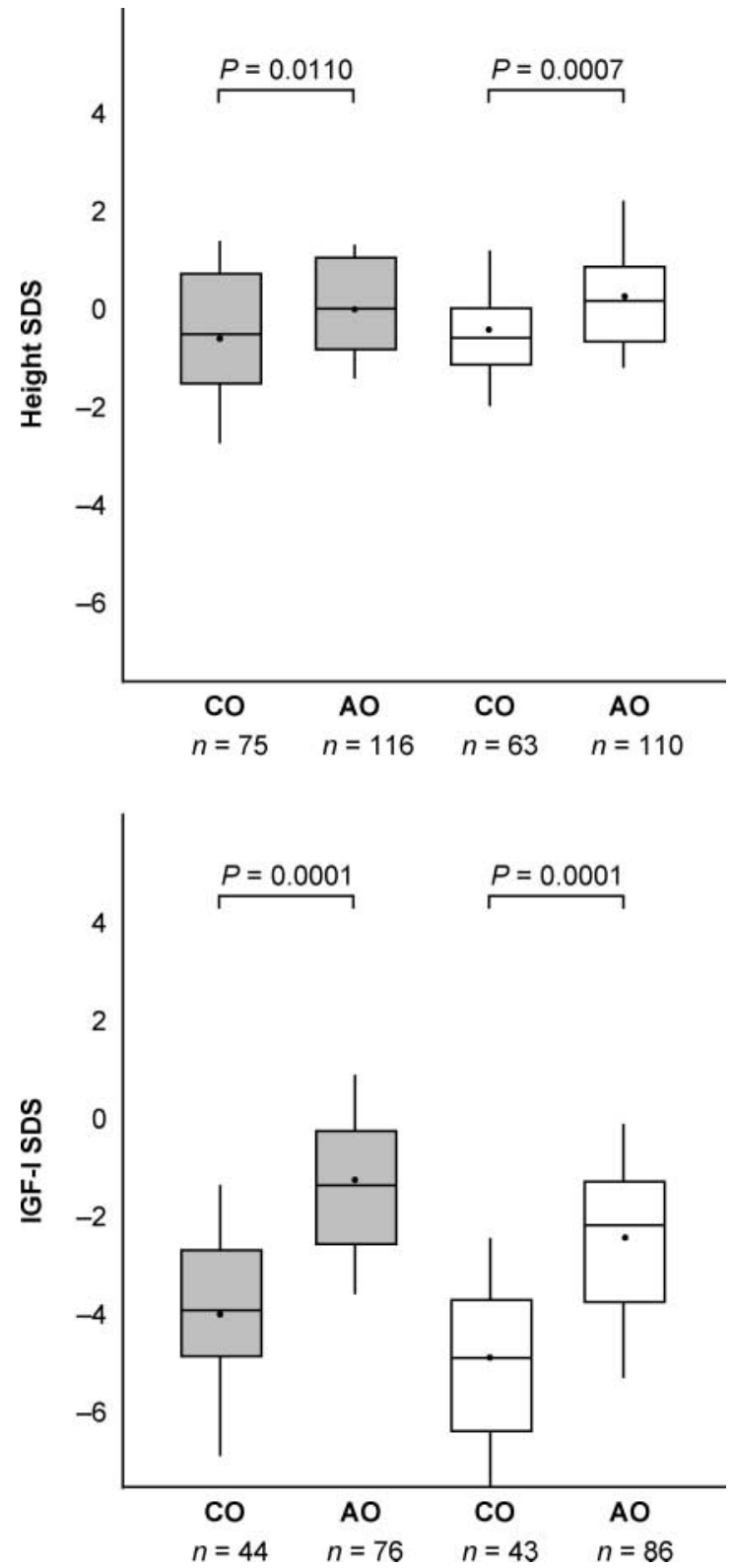

Figure 2 Height SDS and IGF-I SDS at baseline (time of enrolment in KIMS database). Boxes show median with 25th and 75th centiles, whiskers are 10th and 90th centiles. The means are shown as black dots. $\square$, Male; $\square$, female.

years in $\mathrm{AO}(P=0.0026)$ patients; $78.3 \%$ of $\mathrm{CO}$ patients $(n=46)$ had required induction of menarche, whereas $92.1 \%$ of AO patients $(n=63)$ had spontaneous menarche.

\section{Metabolic features (Table 4)}

In males the mean weight of $\mathrm{CO}$ patients was $84.6 \pm 27.3 \mathrm{~kg}$ compared with $92.5 \pm 20.1 \mathrm{~kg}$ for $\mathrm{AO}$ patients $(P=0.0014)$. The BMI (mean for $\mathrm{CO}$ males $28.5 \pm 7.5$, for AO males 30.2 $\pm 5.5, P=0.0194$ ) and

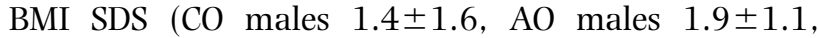

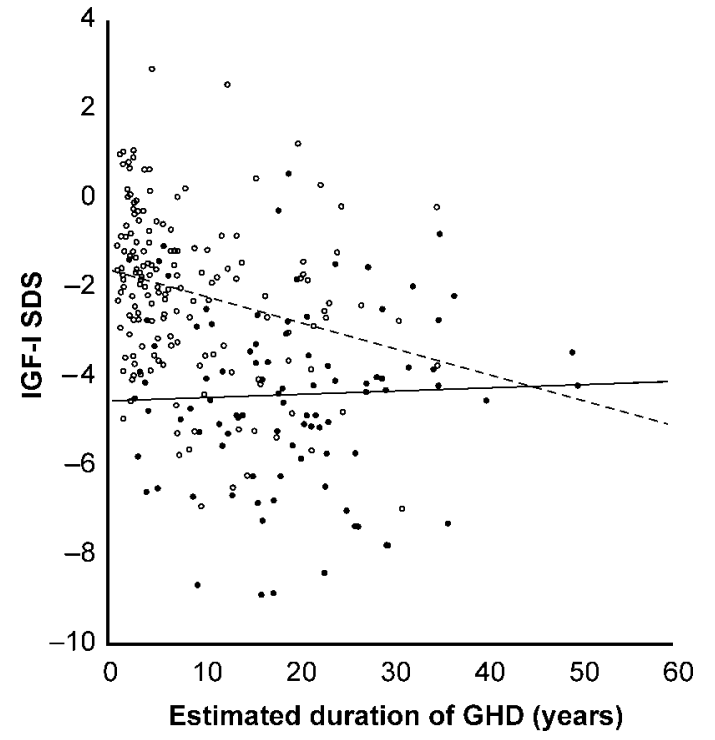

Figure 3 Correlation of IGF-I SDS with the estimated duration of GHD. and solid line, childhood onset disease; $\bigcirc$ and broken line, adult onset disease.

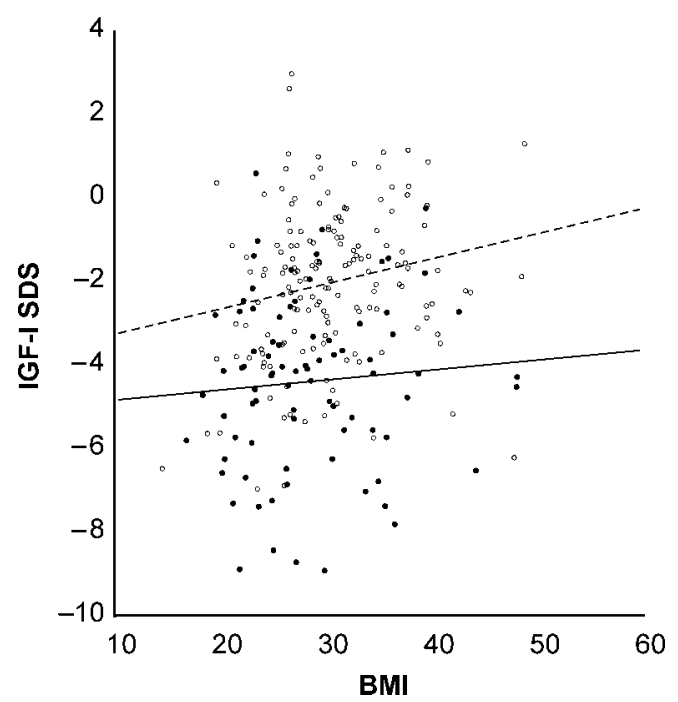

Figure 4 Correlation of IGF-I SDS with BMI. - and solid line, childhood onset disease; $\bigcirc$ and broken line, adult onset disease.

Table 3 Data relating to $\mathrm{GH}$ and other hormone deficiencies (mean \pm S.D.).

\begin{tabular}{lccc}
\hline & CO & AO & $\boldsymbol{P}$ \\
\hline Height (cm) & $165.5 \pm 10.7$ & $168.9 \pm 9.6$ & 0.0018 \\
Height SDS & $-0.54 \pm 1.4$ & $-0.05 \pm 1.2$ & 0.0001 \\
IGF-I SDS & $-4.42 \pm 2.03$ & $-2.05 \pm 1.83$ & 0.0001 \\
LH/FSH deficit \% & 95.3 & 94.2 & $\mathrm{~ns}$ \\
ACTH deficit \% & 86.8 & 89.6 & $\mathrm{~ns}$ \\
TSH deficit \% & 94.1 & 92.2 & $\mathrm{~ns}$ \\
AVP deficit \% & 60.5 & 63.5 & $\mathrm{~ns}$ \\
Panhypopituitary \% & 57.9 & 59.8 & $\mathrm{~ns}$ \\
\hline
\end{tabular}

AVP, arginine vasopressin; ns, not significant. 
Table 4 Metabolic data comparing $\mathrm{CO}$ and $\mathrm{AO}$ males $(\mathrm{M})$ and $\mathrm{CO}$ and $\mathrm{AO}$ females $(\mathrm{F})$. Results are expressed as (means \pm S.D.).

\begin{tabular}{|c|c|c|c|c|c|c|}
\hline & $\mathrm{CO}(\mathrm{M})$ & AO (M) & $P$ & $\operatorname{CO}(\mathrm{F})$ & AO $(F)$ & $\boldsymbol{P}$ \\
\hline Weight $(\mathrm{kg})$ & $84.6 \pm 27.3$ & $92.5 \pm 20.1$ & 0.0014 & $75.4 \pm 20.4$ & $80.2 \pm 18.9$ & 0.0358 \\
\hline BMI & $28.5 \pm 7.5$ & $30.2 \pm 5.5$ & 0.0194 & $29.8 \pm 7.9$ & $30.0 \pm 6.9$ & ns \\
\hline BMI SDS & $1.4 \pm 1.6$ & $1.9 \pm 1.1$ & 0.0306 & $1.8 \pm 1.4$ & $1.8 \pm 1.4$ & ns \\
\hline Waist circumference $(\mathrm{cm})$ & $96.8 \pm 16.0$ & $103.1 \pm 12.0$ & 0.0027 & $93.8 \pm 16.1$ & $95.8 \pm 15.8$ & ns \\
\hline Waist/hip ratio & $0.99 \pm 0.16$ & $1.01 \pm 0.18$ & ns & $0.89 \pm 0.08$ & $0.88 \pm 0.08$ & ns \\
\hline Lean tissue (BIA) (kg) & $59.7 \pm 13.8$ & $64.2 \pm 9.1$ & $\mathrm{~ns}$ & $47.7 \pm 10.5$ & $49.5 \pm 11.9$ & ns \\
\hline Fat tissue $(\mathrm{BIA})(\mathrm{kg})$ & $25.6 \pm 14.5$ & $26.0 \pm 10.1$ & ns & $32.6 \pm 13.9$ & $32.9 \pm 15.1$ & ns \\
\hline Cholesterol $(\mathrm{mmol} / \mathrm{l})$ & $5.74 \pm 1.54$ & $6.12 \pm 1.39$ & ns & $5.82 \pm 1.22$ & $6.19 \pm 1.21$ & ns \\
\hline $\mathrm{HDL}(\mathrm{mmol} / \mathrm{l})$ & $1.08 \pm 0.36$ & $1.04 \pm 0.32$ & ns & $1.35 \pm 0.34$ & $1.30 \pm 0.43$ & ns \\
\hline $\mathrm{LDL}(\mathrm{mmol} / \mathrm{l})$ & $3.52 \pm 1.20$ & $3.84 \pm 1.19$ & ns & $3.63 \pm 1.08$ & $3.79 \pm 1.09$ & ns \\
\hline Triglycerides $(\mathrm{mmol} / \mathrm{l})$ & $2.71 \pm 2.68$ & $3.39 \pm 3.21$ & ns & $1.85 \pm 0.83$ & $2.53 \pm 1.45$ & 0.0044 \\
\hline
\end{tabular}

ns, not significant.

$P=0.0306)$ were also significantly less in CO than in AO patients (Fig. 5). For females the mean weight of CO patients $(75.4 \pm 20.4 \mathrm{~kg})$ was less than AO patients $(80.2 \pm 18.9 \mathrm{~kg})(P=0.0358)$, but the BMI did not differ significantly (CO females $29.8 \pm 7.9$ and AO females 30.0 \pm 6.9 ), nor was there a significant difference when BMI SDS was used (mean CO $1.8 \pm 1.4$ and AO 1.8 \pm 1.4 ). Obesity, defined as BMI $\geq 30.0$ for males and BMI $\geq 28.6$ for females, was more prevalent in AO (51.8\%) compared with CO patients $(39.1 \%$, $P=0.0191)$ and was more apparent in females $(42.9 \%$ of $\mathrm{CO}$ and $56.9 \%$ of $\mathrm{AO})$ than in males (36.0\% of $\mathrm{CO}$ and $47.0 \%$ of AO). The BMI SDS did correlate with the number of surgical procedures $(\mathrm{R}=0.123, P=0.025)$, but it was unrelated to the peak GH. There was no correlation of obesity with type of surgery, nor did obesity relate to use of radiotherapy.

The waist circumference was significantly less in $\mathrm{CO}$ than in AO patients $(P=0.0203)$, and in male $\mathrm{CO}$ vs

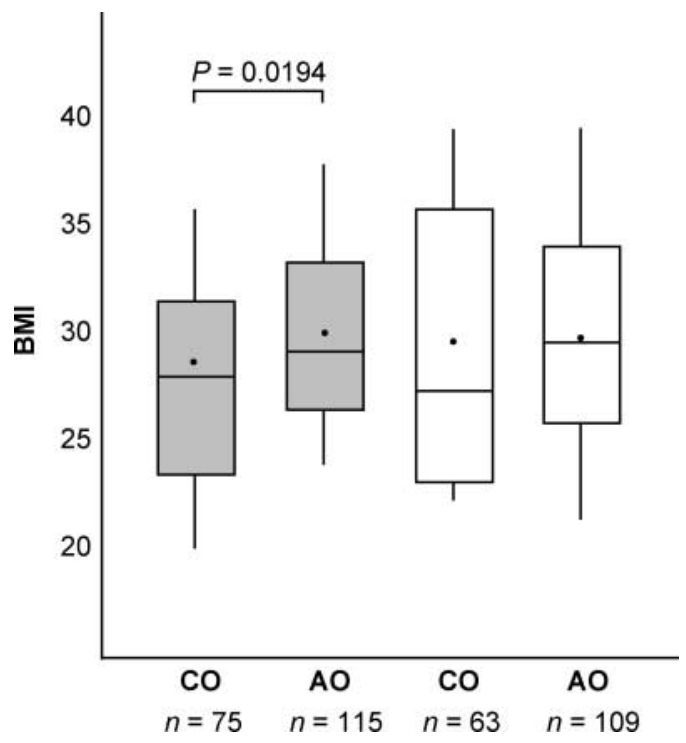

Figure $5 \mathrm{BMI}$ at baseline. Boxes show median with 25th and 75th centiles, whiskers are 10th and 90th centiles. The means are shown as black dots. $\square$, Male; $\square$, female. male AO patients $(P=0.0027)$; in male $\mathrm{CO}$ patients it was above the level considered acceptable. In females, waist circumference did not differ between $\mathrm{CO}$ and $\mathrm{AO}$ patients, but in both groups it was well above the level considered acceptable. The waist circumference correlated strongly with BMI SDS in both CO and AO patients. The waist-hip ratio (WHR) did not differ between $\mathrm{CO}$ and $\mathrm{AO}$ males (0.99 vs 1.01) or females (0.89 vs 0.88$)$. In all groups the WHR was at or above the reference range, indicating that, in general, patients with craniopharyngioma have increased or high/normal WHR and waist circumference, consistent with the BMI in the overweight or obese range.

Body composition was measured by DEXA in 46 patients and by BIA in 132 patients. The data were analysed separately, but no difference for either lean body mass or fat mass was seen in males or females between $\mathrm{CO}$ and AO patients, with either BIA or DEXA.

The lipid data for males and females are shown in Fig. 6. The mean cholesterol was lower in the total group of CO compared with AO patients $(5.78 \pm 1.39$ vs $6.16 \pm 1.29 \mathrm{mmol} / \mathrm{l}, P=0.0143$ ), but when males and females were analysed separately no differences were seen. However, in all groups the cholesterol was elevated. Triglycerides were also elevated or were in the high/normal range and were again lower in $\mathrm{CO}$ $(2.31 \pm 2.07 \mathrm{mmol} / \mathrm{l})$ than in $\mathrm{AO}(2.93 \pm 2.45 \mathrm{mmol} / \mathrm{l})$ patients $(P=0.0017)$; for males this difference was not significant whereas for females it was $(P=0.0044)$. HDL-cholesterol levels for CO males $(1.08 \pm 0.36 \mathrm{mmol} / \mathrm{l})$ and females $(1.35 \pm 0.34 \mathrm{mmol} / \mathrm{l})$ were similar to those in $\mathrm{AO}$ patients $(1.04 \pm 0.32$ and $1.30 \pm 0.43 \mathrm{mmol} / \mathrm{l})$. LDL-cholesterol did not differ between groups (mean for CO patients 3.58 \pm 1.13 and for AO patients $3.81 \pm 1.13 \mathrm{mmol} / \mathrm{l})$.

Fasting blood glucose: in CO patients $(n=125)$ the mean blood glucose was $4.72 \pm 1.47 \mathrm{mmol} / \mathrm{l}$; six $(4.8 \%)$ patients had levels above the reference range and nine below it. In AO patients $(n=214)$, mean blood glucose was $4.84 \pm 1.34 \mathrm{mmol} / \mathrm{l}$, with $17(7.9 \%)$ having levels above the reference range and 14 below it. The blood glucose correlated with BMI SDS $(\mathrm{R}=0.169, P=0.002)$, and this was true for both 

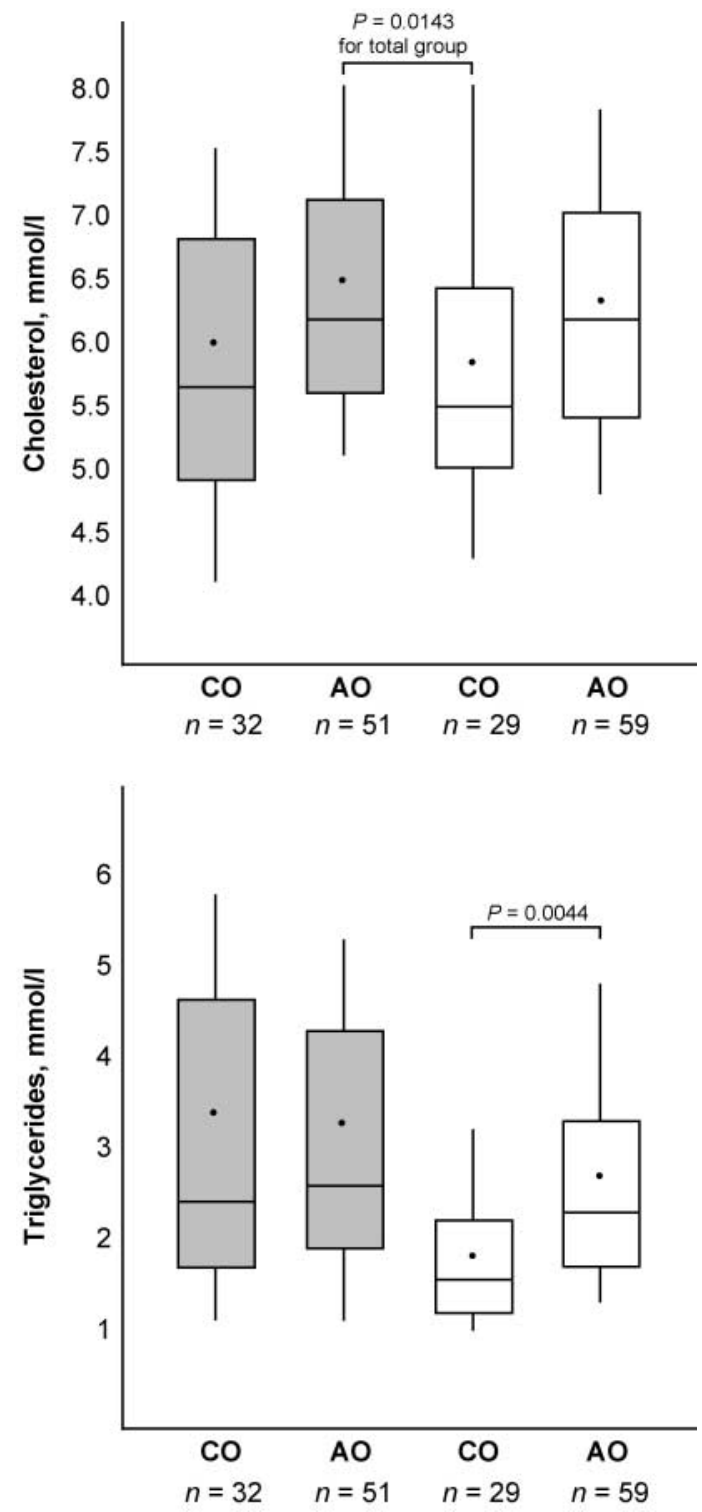

Figure 6 Blood lipids at baseline, showing cholesterol and triglyceride levels. Boxes show median with 25th and 75th centiles, whiskers are 10th and 90th centiles. The means are shown as black dots. Males, $\quad$; females, $\square$.

$\mathrm{CO}$ and $\mathrm{AO}$ patients. The HbA1c was normal or low in $79 \mathrm{CO}$ and $141 \mathrm{AO}$ patients, and was elevated in eight (8.9\%) CO and 21 (12.8\%) AO patients. There was no difference between $\mathrm{CO}$ and $\mathrm{AO}$ patients with respect to median levels of blood glucose and HbA1c. Diabetes was already known to be present in four $(2.6 \%) \mathrm{CO}$ and six $(2.5 \%)$ AO patients.

\section{Other clinical features}

Data for visual fields were missing or unknown in $44.1 \%$ of $\mathrm{CO}$ and $45.6 \%$ of $\mathrm{AO}$ patients, but in the
216 patients where data were available, $56.5 \%$ of $\mathrm{CO}$ and $64.1 \%$ of AO patients had visual field defects.

The mean arterial pressure was $88.22 \pm 10.97 \mathrm{mmHg}$ in $\mathrm{CO}$ patients and was significantly higher in $\mathrm{AO}$ patients at $94.35 \pm 11.60 \mathrm{mmHg}(P=0.0001)$, but this difference was shown by MLR to be an age effect.

The figures for coexisting disease at baseline show: 0 CO patients, four (1.7\%) AO patients with ischaemic heart disease; four $(2.6 \%) \mathrm{CO}$ patients, 19 (7.9\%) AO patients with hypertension; one $(0.7 \%) \mathrm{CO}$ patient, seven $(2.90 \%)$ AO patients with stroke.

Previous fractures were recorded for $17.8 \%$ of $\mathrm{CO}$ and $25.3 \%$ of AO patients, of which the majority in each age group were fractures of the radius. Unfortunately, the data for bone density are not suitable for analysis as this parameter was measured in only a few patients.

\section{Psychosocial features}

Quality of life was reduced in all groups: the QoLAGHDA score was generally higher (worse) in AO compared with CO patients: $11.27 \pm 6.93$ vs $9.56 \pm 6.83$ $(P=0.0485)$; when adjusted for age by multivariate analysis the significance disappears. These AGHDA scores compare with scores for the general population of up to 3.3 for men and 4.6 for women. Among the CO patients females appear to score worse than males: females $10.33 \pm 7.00$ vs males $8.85 \pm 6.62$, but the difference was not significant; there was no gender difference in the AO group (AO females

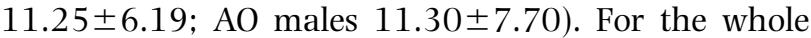
cohort the QoL-AGHDA score correlated with the age of onset of the craniopharyngioma $(P=0.011)$, and with the age of onset of GHD $(P<0.001)$, but not with the duration of the GHD. The QoL-AGHDA score correlated strongly with the BMI in the $\mathrm{AO}$ $(P<0.001)$ but not in the CO group; waist circumference correlated with the AGHDA score in the AO $(P=0.005)$, but not in the CO patients; there was no correlation with WHR. There was a barely positive correlation of QoL-AGHDA with IGF-I SDS $(\mathrm{R}=0.14$, $P=0.043)$. The NHP score was also higher in AO compared with $\mathrm{CO}$ patients $(8.80 \pm 6.38$ vs $5.84 \pm 5.43$, $P=0.0036)$, although values for only 138 patients are documented.

Data for civil status were documented in four categories: unmarried, married/cohabiting, widow/widower, and divorced/separated. Of those in whom these data were available $(n=263), 81.6 \%$ of the CO group were in the unmarried category compared with $25 \%$ AO patients; $14.6 \%$ of CO patients were married or cohabiting compared with $63.1 \%$ of $\mathrm{AO}$ patients. The majority $(68 \%)$ of the unmarried CO patients were aged $<30$ years.

In 257 patients data were available for employment: of these $257,8.9 \%$ of $\mathrm{CO}$ and $3.8 \%$ of $\mathrm{AO}$ patients were unemployed and a further $15.8 \%$ of $\mathrm{CO}$ and $19.2 \%$ of 
AO patients were on sickness benefit at the time of entry to the database. AO patients were more likely to be cigarette smokers compared with $\mathrm{CO}$ patients (AO 27\%, CO 11\%; P $<0.001)$.

\section{Discussion}

This very large series of patients has provided a powerful tool for the analysis of various features of craniopharyngioma. This is the largest series of patients with CO craniopharyngioma to be studied in adult life and the length of follow-up since diagnosis, with a mean of 17 years, is impressive. Numerous series of patients with GHD of diverse aetiologies have been reported previously but this study highlights the value of studying GHD patients with a single aetiology. However, the study has some limitations: data recorded at the time of initial diagnosis were not available; furthermore there is inevitably a degree of selectivity, in that not all patients with GHD have been entered into the database. Also a directly comparable control population is not available and comparisons have been made with control data from published series.

The most striking finding from this study is the generally poor state of health of patients treated for craniopharyngioma, with respect to endocrine and metabolic function, as well as the relatively poor quality of life. The majority of both $\mathrm{CO}$ and AO patients have panhypopituitarism, and $60 \%$ have DI. Almost all subjects are overweight or obese, and have elevated blood lipids. The quality of life as assessed by QoL-AGHDA and NHP is poor in both groups of patients. Although surgery may be a contributory factor to the endocrine deficit, it cannot be held to be primarily responsible since even the non-operated patients had severely compromised pituitary function with a mean of 2.9 hormone deficiencies. DI was less common (although it still occurred in 33\%) in the non-operated patients, which probably relates to the severity of the disease. In another large series, diabetes insipidus increased from $16.1 \%$ preoperatively to $59.4 \%$ postoperatively; GHD and secondary hypogonadism were found preoperatively in $73 \%$ and $77 \%$ of patients respectively, ACTH deficiency in $32 \%$ and TSH deficiency in $25 \%$ (15). However, in a study from the USA, Shin et al. (16) found that $95 \%$ of patients presented with hypopituitarism and as many as $67 \%$ had preoperative visual or other neurological deficits.

The features in adults with CO craniopharyngioma are in many respects similar to those in patients in whom the disease has presented in adulthood. The CO group is younger but had had GHD for twice as long as the AO group. The major differences which call for comment are those of height and IGF-I: not surprisingly the final height in the $\mathrm{CO}$ patients is below that of adults, since all these patients were GHD, not all had received GH in childhood and even when $\mathrm{GH}$ had been given it is likely that it was started at a relatively late age and that the height at diagnosis was reduced, both of which are factors known to influence final height (17). However, although this difference is significant the height is only $<1$ SDS from the expected. In contrast, the IGF-I SDS in CO patients is grossly reduced at -4.4 and differs significantly from IGF-I SDS in patients with GHD of AO; this difference in IGF-I between $\mathrm{CO}$ and $\mathrm{AO}$ patients confirms previous observations in patients with GHD of mixed aetiology (18-22). There was a negative correlation of IGF-I with the duration of GHD in AO patients, which is in keeping with another large series of KIMS patients with hypopituitarism (23). However, the IGF-I in CO patients who had received $\mathrm{GH}$ in childhood was not higher than in those who had not, suggesting that the length of time since the last exposure to $\mathrm{GH}$ was not directly responsible. There is no clear explanation for this finding of very low IGF-I, although other authors (19) have speculated that childhood GH deficiency may program the subsequent relationship between GH and IGF-I in adult life. A further possible explanation for the very low IGF-I in CO patients may perhaps relate to the delayed puberty: most of the CO patients had had delayed puberty, compared with approximately $11.5 \%$ in $\mathrm{AO}$ males and $8 \%$ in $\mathrm{AO}$ females. Delayed puberty indicates a testosterone deficit in males; testosterone is related to IGF-I levels in healthy males (24) and administration of testosterone increases IGF-I in healthy subjects but not in hypopituitary individuals (25), suggesting that early or longstanding deficiency of testosterone could exacerbate the IGF-I deficit. Although in females the situation is more complicated, it is known that endogenous oestradiol stimulates IGF-I in young women (26), so a similar mechanism could also be postulated for the IGF-I deficit in women with $\mathrm{CO}$ GHD. In the small number of $\mathrm{AO}$ patients with delayed puberty it seems likely that this may have been an early sign of the disease, suggesting that the onset of the disease may have been earlier than previously supposed.

Hypothalamic disease or damage is known to be associated with the development of obesity. A recent study (27) found hypothalamic damage, due to tumour, surgery, or radiation, to be the primary cause of obesity in survivors of childhood brain tumours. Craniopharyngioma carried the highest risk factor for obesity of any childhood brain tumour and those with DI had the most severe weight gain. The very high incidence of overweight or obesity in the present study is no surprise - although this was a feature common to both groups, AO patients, particularly males, were significantly more obese than their $\mathrm{CO}$ counterparts, as judged by weight, BMI SDS and waist circumference. Multivariate analysis showed this to be a true difference, not attributable to the greater age of the AO group.

The BMI correlated with IGF-I; this was unexpected and requires explanation. BMI is increased in patients with GHD, but if the BMI is an indicator of the 
severity of the GHD then one might expect a negative correlation with IGF-I; in fact the high BMI in this series reflects the hypothalamic obesity, which is known to be associated with hyperinsulinaemia (28), and may, in turn, be contributing to the relatively higher IGF-I levels in the more obese patients. The correlation of BMI SDS with the presence of DI is consistent with hypothalamic damage as the cause, and confirms the finding of Lustig et al. (27).

GHD is also associated with changes in body composition (29-31), characterized by an increase in fat tissue and decreased lean body mass. The expected increase in fat mass was confirmed in this study, but BIA did not show any difference in fat mass or lean body mass between the two groups of patients. The blood lipids, which were high in all groups, showed some subtle differences with slightly higher levels of cholesterol and triglycerides in the AO patients.

Diabetes mellitus was known to be present in $2.6 \%$ of the cohort, but with a further percentage having elevated HbA1c and/or blood glucose; this applied equally to those of younger age and may represent an increased rate of diabetes compared with a prevalence of diabetes of $1 \%$ in a British population (32). However, the prevalence of diabetes in a Swedish population in 1995 was estimated as $3.20 \%$ (33), so it is impossible to draw conclusions as to whether, for this international cohort of patients, diabetes is more frequent than expected.The blood glucose correlated with the BMI SDS; increasing obesity as defined by BMI has been associated in several studies with a risk of developing Type 2 diabetes mellitus, and in a longitudinal followup study in the same UK community (34) the development of diabetes was predicted by BMI as well as by fasting blood glucose and triglycerides. Thus if there is indeed an increase in prevalence of diabetes in craniopharyngioma patients it may be, at least in part, secondary to the raised BMI and the raised triglycerides.

The fracture rate appears to be unexpectedly high. Rosen et al. (35) showed a threefold increase in fracture rate in hypopituitary patients from a single centre compared with a group of mixed European population (the MONICA project). The odds ratios for fracture frequency were 3.97 and 2.64 in men and women respectively. Patients with GHD of mixed aetiology in the KIMS database were previously compared with age- and sex-matched non-GHD population data from the European Vertebral Osteoporosis Study (EVOS) (36) and showed a similar increase. The control fracture rate in that study was $7.8 \%$ for men and $9.5 \%$ in women, which is well below that found here in both the $\mathrm{CO}$ and $\mathrm{AO}$ craniopharyngioma patients, although the patients are younger than those control subjects so would be expected to have a lower rate. The EVOS controls had mean ages of $>60$ years, yet the prevalence of fractures was lower than those found in this study, confirming the importance of GHD with respect to osteoporosis even at a rather young age.
Both the indices used (QoL-AGHDA and NHP) to assess quality of life have been well validated for the purpose and have been used to compare differences between groups of patients $(12-14,37,38)$; they indicated a generally reduced quality of life, as has been found in previous studies of GHD $(17,37)$. In a large European study, the expected score for the general population on the AGHDA scale was up to 3.3 for men and 4.6 for women (38), compared with the mean for a large series of hypopituitary patients of 7.1 (23), whereas in this series of patients with hypopituitarism due to craniopharyngioma the mean AGHDA score was considerably greater at 11.3 . Notable factors that correlated with this poor score are the age at which the disease and the GHD developed and, in AO disease, the BMI and waist circumference. Although the CO group appeared to score better than the AO group, this was shown by multivariate analysis to be attributable to age; the NHP score was worse in the AO patients, consistent with the findings of an earlier study examining GHD of mixed aetiology (20). A previous study (37) found that the NHP score was also higher than that in matched controls, indicating a higher level of perceived health problems among the patients, but also there was a tendency to a higher frequency of early retirement and an increase in the number of disablement pensions. Our study shows a similar trend, with $15.8 \%$ of $\mathrm{CO}$ and $19.2 \%$ of $\mathrm{AO}$ patients on sickness benefit, although there is no adequate control group for this international cohort. The implication is that for craniopharyngioma the poor quality of life is due, in some measure, to features of the disease, particularly the BMI, other than the GHD.

In this study we have not attempted to examine the effects of treatment for the underlying craniopharyngioma, nor the outcome with respect to recurrence or mortality, as these important questions will form the subject for a separate report.

The findings reported here for craniopharyngiomas are similar in some but not all respects to those reported in two previous papers comparing GHD of mixed aetiologies $(21,22)$. Our study of craniopharyngioma patients who also had GHD indicates some of the features to be attributable to the GHD, but in addition there is evidence for considerable hypothalamic damage, in that the craniopharyngioma patients have a high frequency of additional hormone deficits, delayed puberty in the CO group, DI, and obesity. Some of the metabolic features are a consequence primarily of the hypothalamic damage, from the tumour or its treatment, rather than the GHD. It will therefore be interesting to assess the effects of $\mathrm{GH}$ treatment in this group of patients.

Craniopharyngioma patients, whether of $\mathrm{CO}$ or $\mathrm{AO}$, are very high risk individuals in metabolic terms, and this will contribute to the high $\operatorname{SMR}(4,5)$. Adults with CO craniopharyngioma were shorter than patients with AO disease, and had lower IGF-I, lower 
BMI, less obesity and slightly lower blood lipid levels and a slightly better quality of life.

\section{Acknowledgements}

We thank all of the investigators involved in KIMS for their contribution to the data.

\section{References}

1 Bunin GR, Surawicz TS, Witman PA, Preston-Martin S, Davis F \& Bruner JM. The descriptive epidemiology of craniopharyngioma. Journal of Neurosurgery $1998 \mathbf{8 9} 547-551$.

2 Blair V \& Burch JM. Patterns and temporal trends in the incidence of malignant disease in children: II. Solid tumours of childhood. European Journal of Cancer 1994 30A 1498-1511.

3 Fahlbusch R, Honegger J, Paulus W, Huk W \& Buchfelder M. Surgical treatment of craniopharyngiomas: experience with 168 patients. Journal of Neurosurgery 199990 237-250.

4 Bülow B, Attewell R, Hagmar L, Malmström P, Nordström CH \& Erfurth EM. Postoperative prognosis in craniopharyngioma with respect to cardiovascular mortality, survival, and tumor recurrence. Journal of Clinical Endocrinology and Metabolism $1998 \mathbf{8 3}$ $3897-3904$

5 Tomlinson JW, Holden N, Hills RK, Wheatley K, Clayton RN, Bates AS, Sheppard MC, Stewart PM \& West Midlands, Prospective Hypopituitary Study Group. Association between premature mortality and hypopituitarism. Lancet 2001357 425-431.

6 Price DA, Wilton P, Jonsson P, Albertsson-Wikland K, Chatelain P, Cutfield W \& Ranke MB. Efficacy and safety of growth hormone treatment in children with prior craniopharyngioma: an analysis of the KIGS database from 1988 to 1996. Hormone Research 1998 49 91-97.

7 Tiulpakov AN, Mazerkina NA, Brook CGD, Hindmarsh PC, Peterkova VA \& Gorelyshev SK. Growth in children with craniopharyngioma following surgery. Clinical Endocrinology 199849 $733-738$.

8 Lie RF, Scmitz JM, Pierre KJ \& Gochman N. Cholesterol oxidasebased determination, by continuous-flow analysis, of total and free cholesterol in serum. Clinical Chemistry 197622 $1627-1630$.

9 Lopez-Virella MF, Stone P, Ellis S \& Colwell JA. Cholesterol determination in high-density lipoproteins separated by three different methods. Clinical Chemistry 197723 882-884.

10 Fossati P \& Prencipe L. Serum triglycerides determined colorimetrically with an enzyme that produces hydrogen peroxide. Clinical Chemistry 198228 2077-2080.

11 Friedewald WT, Levy RI \& Fredrickson DS. Estimation of the concentration of low-density lipoprotein cholesterol in plasma, without use of the preparative ultracentrifuge. Clinical Chemistry $197218499-502$.

12 Doward LC. The development of the AGHDA score: a measure to assess quality of life of adults with growth hormone deficiency. Quality of Life Research 19954 420-421.

13 Holmes SJ, McKenna SP, Doward LC, Hunt SM \& Shalet SM. Development of a questionnaire to assess the quality of life of adults with growth hormone deficiency. Endocrinology and Metabolism $1995263-69$.

14 McKenna SP, Doward LC, Alonso J, Kohlmann T, Niero M, Prieto L \& Wiren L. The QoL-AGHDA: an instrument for the assessment of quality of life in adults with growth hormone deficiency. Quality of Life Research 19998 373-383.

15 Honegger J, Buchfelder M \& Fahlbusch R. Surgical treatment of craniopharyngiomas: endocrinological results. Journal of Neurosurgery $199990251-257$.

16 Shin JL, Asa SL, Woodhouse LJ, Smyth HS \& Ezzat S. Cystic lesions of the pituitary: clinicopathological features distinguishing craniopharyngioma, Rathke's cleft cyst, and arachnoid cyst. Journal of Clinical Endocrinology and Metabolism 199984 3972-3982.

17 Drake WM, Howell SJ, Monson SJ \& Shalet SM. Optimizing GH therapy in adults and children. Endocrine Reviews 200122 $425-450$.

18 Hilding A, Hall K, Wivall-Helleryd IL, Sääf M, Melin AL \& Thorén M. Serum levels of insulin-like growth factor-I in 152 patients with growth hormone deficiency, aged 19-82 years, in relation to those in healthy subjects. Journal of Clinical Endocrinology and Metabolism 199984 2013-2019.

19 Lissett CA, Murray RD \& Shalet SM. Timing of onset of growth hormone deficiency is a major influence on insulin-like growth factor I status in adult life. Clinical Endocrinology 200257 35-40.

20 Attanasio AF, Lamberts SW, Matranga AM, Birkett MA, Bates PC, Valk NK, Hilsted J, Bengtsson BA \& Strasburger CJ. Adult growth hormone $(\mathrm{GH})$-deficient patients demonstrate heterogeneity between childhood onset and adult onset before and during human GH treatment. Journal of Clinical Endocrinology and Metabolism $19978282-88$.

21 Koranyi J, Svensson J, Götherström G, Sunnerhage K, Bengtsson B-A \& Johannsson G. Baseline characteristics and the effects of five years of $\mathrm{GH}$ replacement therapy in adults with GH deficiency of childhood or adulthood onset: a comparative, prospective study. Journal of Clinical Endocrinology and Metabolism $2001864693-4699$.

22 Attanasio AF, Bates PC, Ho KKY, Webb SM, Ross RJ, Strasburger CJ, Bouillon R, Crowe B, Selander K, Valle D \& Lamberts SWJ, on behalf of the Hypopituitary Control and Complications Study International Advisory Board. Human growth hormone replacement in adult hypopituitary patients: long-term effects on body composition and lipid status - 3-year results from the HypoCCS database. Journal of Clinical Endocrinology and Metabolism 200287 1600-1606.

23 Abs R, Bengtsson BA, Hernberg-Ståhl E, Monson JP, Tauber JP, Wilton P \& Wüster C. GH replacement in 1034 growth hormone deficient hypopituitary adults: demographic and clinical characteristics, dosing and safety. Clinical Endocrinology $1999 \mathbf{5 0}$ $703-713$.

24 Erfurth EM, Hagmar LE, Saaf M \& Hall K. Serum levels of insulinlike growth factor I and insulin-like growth factor-binding protein 1 correlate with serum free testosterone and sex hormone binding globulin levels in healthy young and middle-aged men. Clinical Endocrinology $1996 \mathbf{4 4}$ 59-64.

25 Fisker S, Nørrelund H, Juul A, Skakkebæk NE, Christiansen JS \& Jørgensen JOL. The growth hormone $(\mathrm{GH})$ - insulin-like growth factor axis during testosterone replacement therapy in GH-treated hypopituitary males. Growth Hormone and IGF Research 200111 104-109.

26 Ovesen P, Vahl N, Fisker S, Veldhuis JD, Christiansen JS \& Jorgensen JO. Increased pulsatile, but not basal, growth hormone secretion rates and plasma insulin-like growth factor I levels during the periovulatory interval in normal women. Journal of Clinical Endocrinology and Metabolism 199883 1662-1667.

27 Lustig RH, Post SR, Srivannaboon K, Rose SR, Danish RK, Burghen GA, Xiong X, Wu S \& Merchant TE. Risk factors for the development of obesity in children surviving brain tumors. Journal of Clinical Endocrinology and Metabolism $2003 \mathbf{8 8}$ 611-616.

28 Pinto G, Bussieres L, Recasens C, Souberbielle JC, Zerah M \& Brauner R. Hormonal factors influencing weight and growth pattern in craniopharyngioma. Hormone Research 200053 $163-169$.

29 Salomon F, Cuneo RC, Hesp R \& Sonksen PH. The effects of treatment with recombinant human growth hormone on body composition and metabolism in adults with growth hormone deficiency. New England Journal of Medicine 1989321 1797-1803.

30 Beshyah SA, Freemantle C, Thomas E, Rutherford O, Page B, Murphy M \& Johnston DG. Abnormal body composition and 
reduced bone mass in growth hormone deficient hypopituitary adults. Clinical Endocrinology 199542 179-189.

31 Hoffman DM, O'Sullivan AJ, Freund J \& Ho KK. Adults with growth hormone deficiency have abnormal body composition but normal energy metabolism. Journal of Clinical Endocrinology and Metabolism $1995 \mathbf{8 0} 72-77$.

32 Tunbridge WMG, Evered DC, Hall R, Appleton D, Brewis M, Clark F, Evans JG, Young E, Bird T \& Smith PA. The spectrum of thyroid disease in the community: the Whickham survey. Clinical Endocrinology 19777 481-493.

33 Berger B, Stenström G \& Sundkvist G. Incidence, prevalence, and mortality of diabetes in a large population. Diabetes Care 199922 $773-777$.

34 Vanderpump MPJ, Tunbridge WMG, French JM, Appleton D, Bates D, Rodgers H, Grimley Evans J, Clark F, Tunbridge F \& Young ET. The incidence of diabetes mellitus in an English community: a 20-year follow-up of the Whickham survey. Diabetic Medicine 199613 741-747.

35 Rosen T, Wilhelmsen L, Landin-Wilhemsen K, Lappas G \& Bengtsson BA. Increased fracture frequency in adult patients with hypopituitarism and $\mathrm{GH}$ deficiency. European Journal of Endocrinology 1997137 240-245.
36 Wűster C, Abs R, Bengtsson BA, Bennmarker H, FeldtRasmussen U, Hernberg-Ståhl E, Monson JP, Westberg B \& Wilton P. The influence of growth hormone deficiency, growth hormone replacement therapy, and other aspects of hypopituitarism on fracture rate and bone mineral density. Journal of Bone and Mineral Research $200116398-405$.

37 Rosen T, Wiren L, Wilhelmsen L, Wiklund I \& Bengtsson BA. Decreased psychological well-being in adult patients with growth hormone deficiency. Clinical Endocrinology $1994 \mathbf{4 0}$ $111-116$.

38 Wiren L, Whalley D, McKenna S \& Wilhelmsen L. Application of a disease-specific, quality-of-life measure (QoL-AGHDA) in growth hormone-deficient adults and a random population sample in Sweden: validation of the measure by rasch analysis. Clinical Endocrinology 200052 141-142.

Received 13 September 2004

Accepted 21 December 2004 